\title{
Screening Methanol Poisoning with a Portable Breath Detector
}

\author{
Jan van den Broek ${ }^{1}$, Dario Bischof ${ }^{1}$, Nina Derron ${ }^{2}$, Sebastian Abegg ${ }^{1}$, Philipp Gerber ${ }^{2}$, \\ Andreas T. Güntner ${ }^{*}$, Sotiris E. Pratsinis ${ }^{1}$ \\ ${ }^{1}$ Particle Technology Laboratory, Department of Mechanical and Process Engineering, \\ ETH Zurich, CH-8092 Zurich, Switzerland \\ ${ }^{2}$ Department of Endocrinology, Diabetology, and Clinical Nutrition, University Hospital \\ Zurich, CH-8091 Zurich, Switzerland
}

*corresponding author: andreas.guentner@ptl.mavt.ethz.ch

\section{Contents:}

Supporting Methods: Equation for transformation of blood to breath concentrations

Table S1: Subject data

Figure S1: Data evaluation using weekly calibration

Figure S2: Analyte stability in Tedlar bags

Figure S3: Level of detection of the breath methanol sensor

Figures S4 \& S5: Measured methanol and ethanol concentration of all subjects

Figure S6: Bland-Altman analysis of the relative measurement differences

Figure S7: ROC curves for assessment of poisoning severity by the detector 


\section{Methods}

\section{Blood/breath concentrations}

The following formula was used for conversion of blood to breath alcohol concentrations:

$$
c_{\text {Breath }}(\mathrm{ppm})=\frac{c_{\text {Blood }}\left(\mathrm{mg} \mathrm{L}^{-1}\right)}{r_{\text {Blood } / \text { Breath }} \cdot M_{W}\left(\mathrm{mg} \mathrm{mol}^{-1}\right)} \cdot 24.31 \mathrm{~L} \mathrm{~mol}^{-1} \cdot 10^{6} \mathrm{ppm}
$$

$c_{\text {Blood }}$ : Alcohol concentration in blood

$c_{\text {Breath }}$ : Alcohol concentration in breath

$r_{\text {Blood/Breath }}$ : Blood/breath partition ratio, 2901 for methanol ${ }^{19}$ and 2100 for ethanol ${ }^{22}$ $M_{W}$ : Molecular weight of alcohol, $32.04 \mathrm{~g} \mathrm{~mol}^{-1}$ for methanol and $46.07 \mathrm{~g} \mathrm{~mol}^{-1}$ for ethanol $24.31 \mathrm{~L} \mathrm{~mol}^{-1}$ : Volume occupied per Liter of gas at standard temperature $\left(22{ }^{\circ} \mathrm{C}\right)$ and pressure (1 atm) 
Table S1. Subject data.

\begin{tabular}{|c|c|c|c|c|c|c|}
\hline $\begin{array}{c}\text { Participant } \\
\text { No. }\end{array}$ & Gender & $\begin{array}{c}\text { Age } \\
(\text { years })\end{array}$ & $\begin{array}{c}\text { Weight } \\
\text { (kg) }\end{array}$ & $\begin{array}{c}\text { Beverage } \\
\text { (Ethanol } \\
\text { con.) }\end{array}$ & $\begin{array}{c}\text { Ethanol } \\
(\mathrm{mL})\end{array}$ & $\begin{array}{l}\text { Max. blood ethanol } \\
\text { concentration } \\
\left(\mathrm{mg} \mathrm{L}^{-1}\right)\end{array}$ \\
\hline 1 & $\mathrm{~F}$ & 24 & 53.0 & $\begin{array}{c}\text { Liquor } \\
(37.5 \text { vol } \%)\end{array}$ & 48 & 816 \\
\hline 2 & M & 22 & 92.6 & Liquor & 99 & 782 \\
\hline 3 & M & 23 & 60.0 & $\begin{array}{c}\text { Wine } \\
(13.5 \mathrm{vol} \%)\end{array}$ & 64 & 564 \\
\hline 4 & M & 27 & 78.3 & Wine & 84 & 761 \\
\hline 5 & M & 22 & 75.5 & $\begin{array}{c}\text { Beer } \\
(4.8 \text { vol\%) }\end{array}$ & 81 & 526 \\
\hline 6 & M & 24 & 95.5 & Beer & 102 & 961 \\
\hline 7 & M & 28 & 55.3 & Wine & 59 & 816 \\
\hline 8 & M & 26 & 80.0 & Wine & 85 & 779 \\
\hline 9 & M & 29 & 98.9 & Liquor & 106 & 945 \\
\hline 10 & M & 28 & 65.0 & Wine & 69 & 1030 \\
\hline 11 & $\mathrm{~F}$ & 65 & 62.4 & Wine & 56 & 920 \\
\hline 12 & $\mathrm{~F}$ & 52 & 60.6 & Wine & 55 & 880 \\
\hline 13 & M & 32 & 97.0 & Liquor & 104 & 1257 \\
\hline 14 & $\mathrm{~F}$ & 23 & 68.2 & Beer & 61 & 783 \\
\hline 15 & M & 23 & 70.3 & Beer & 75 & 820 \\
\hline 16 & $\mathrm{~F}$ & 24 & 58.4 & Liquor & 53 & 869 \\
\hline 17 & M & 23 & 75.9 & Beer & 81 & 812 \\
\hline 18 & M & 27 & 78.8 & Beer & 84 & 800 \\
\hline 19 & M & 29 & 109.0 & Liquor & 116 & 935 \\
\hline 20 & M & 26 & 86.2 & Water & 0 & 0 \\
\hline
\end{tabular}




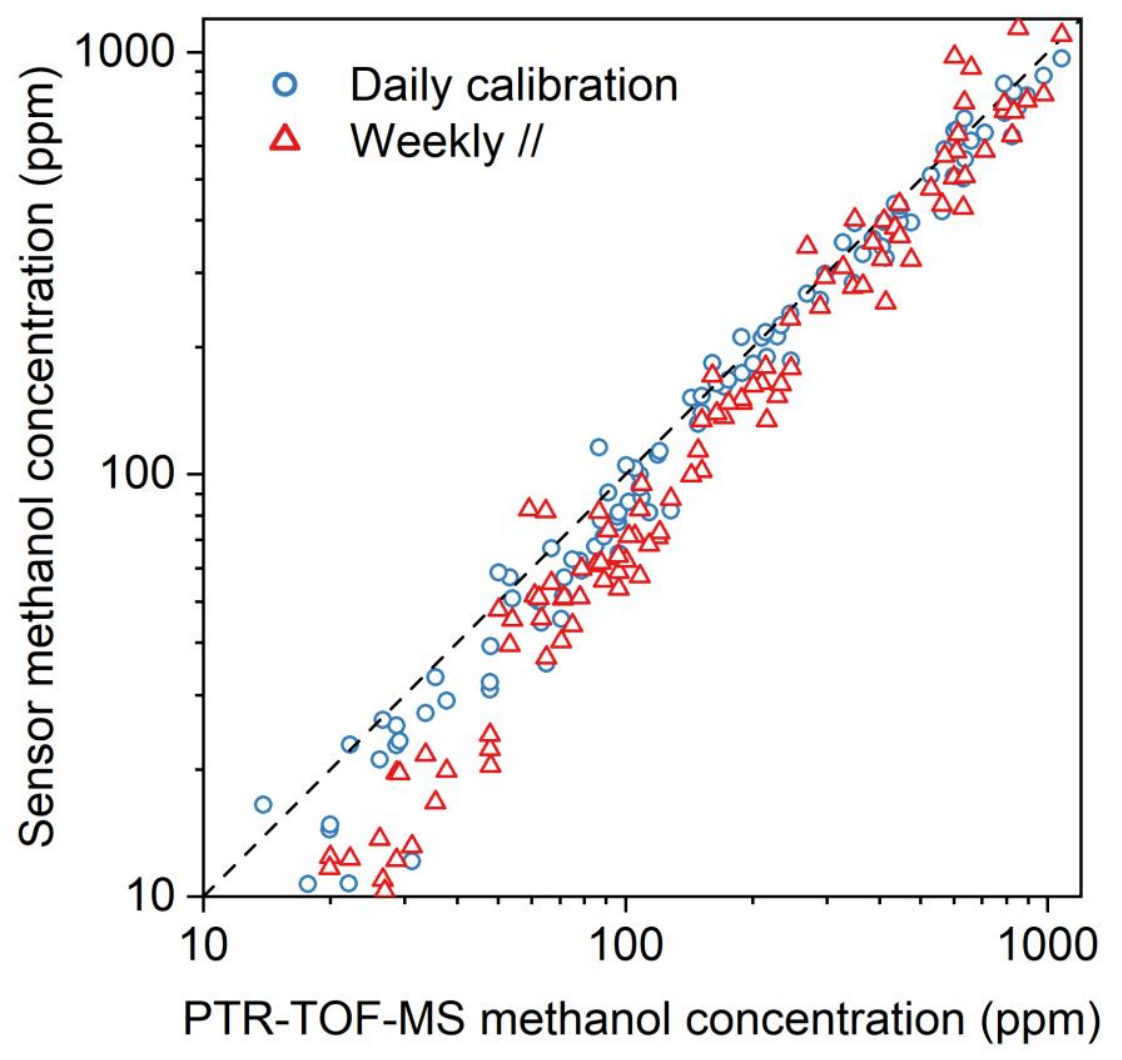

Figure S1. Scatter plot of methanol concentrations in all breath samples when evaluated by daily (blue circles) and weekly calibrations (red triangles).

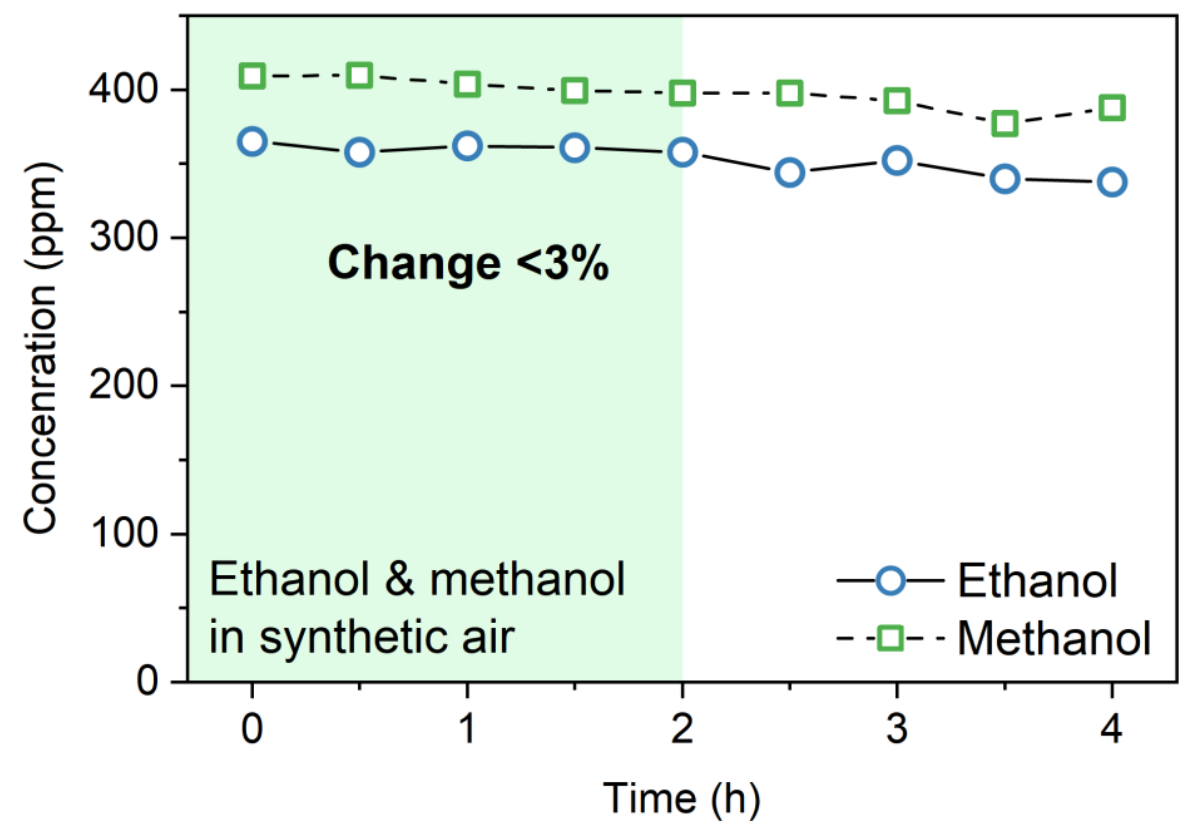

Figure S2. Stability of ethanol (365 ppm, circles) and methanol (409 ppm, squares) in Tedlar bags as measured by PTR-TOF-MS. All samples were analyzed within $2 \mathrm{~h}$ where concentration changes are $<3 \%$ (green shaded). 

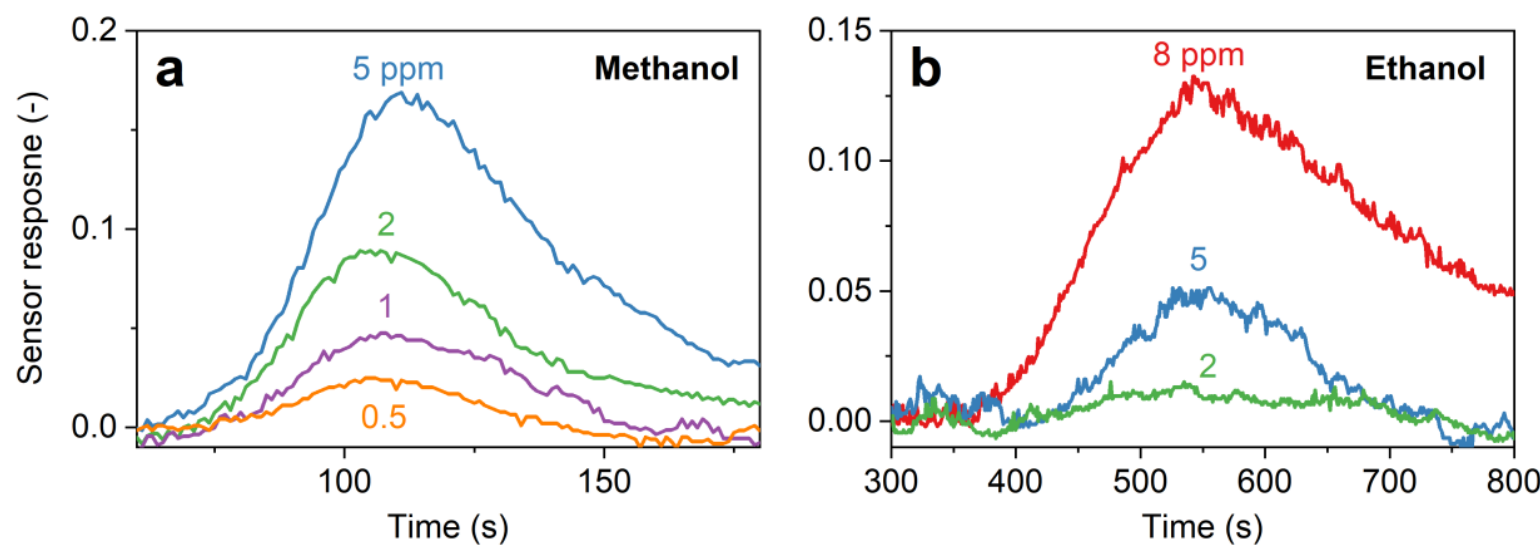

Figure S3. Sensor responses to low concentrations of (a) methanol and (b) ethanol above the level of detection. 

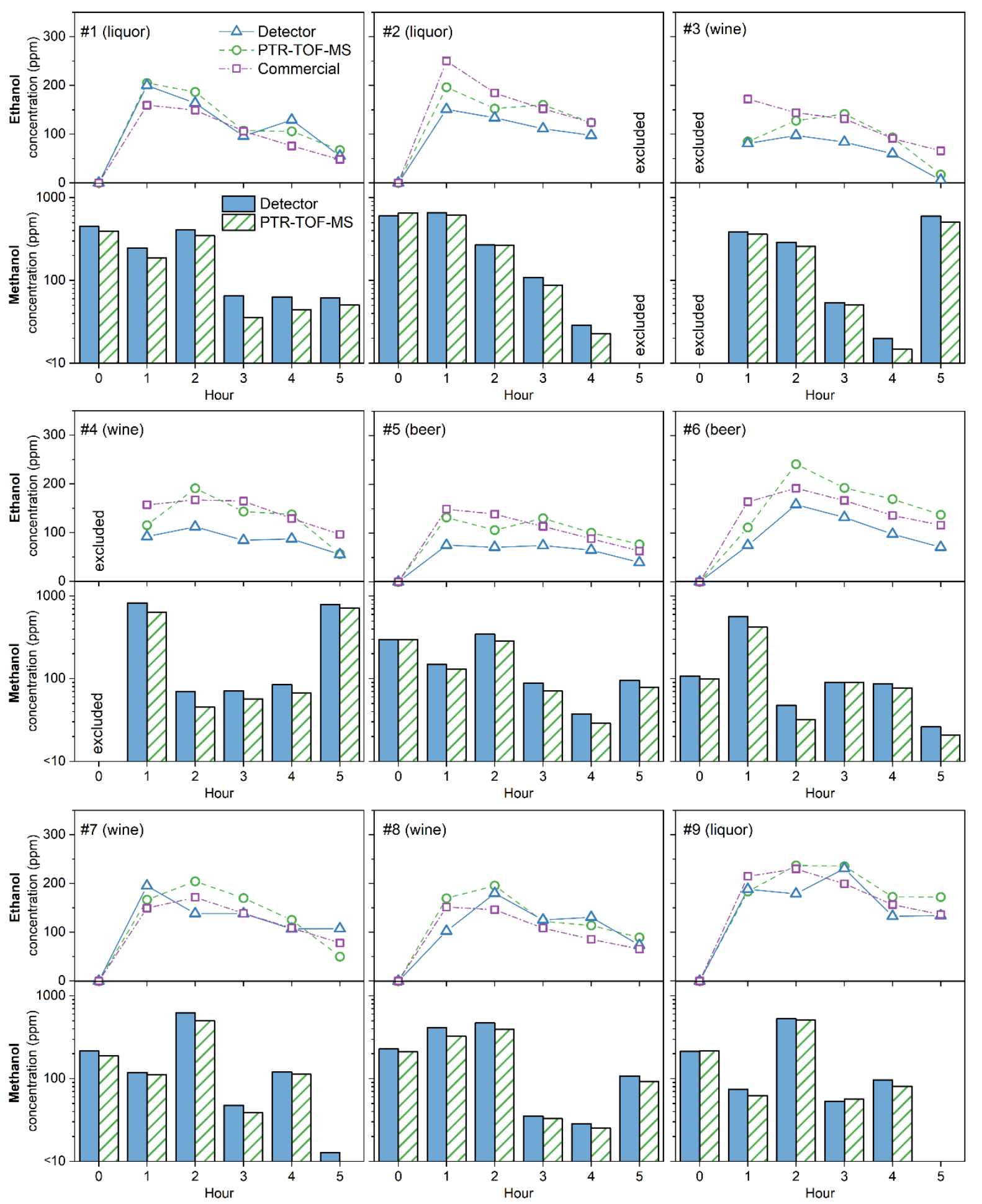

Figure S4. Breath ethanol concentrations (line plots) from volunteers \#1-9 as measured by our detector (triangles), a commercial breathalyzer (Dräger, squares) and the PTR-TOF-MS (circles). Methanol concentrations from the corresponding spiked samples (bar plots) as measured by the detector (solid bars) and PTR-TOF-MS (hatched bars). Excluded data points are due to insufficient breath sample provided by the volunteer or problems during sensor measurements. 

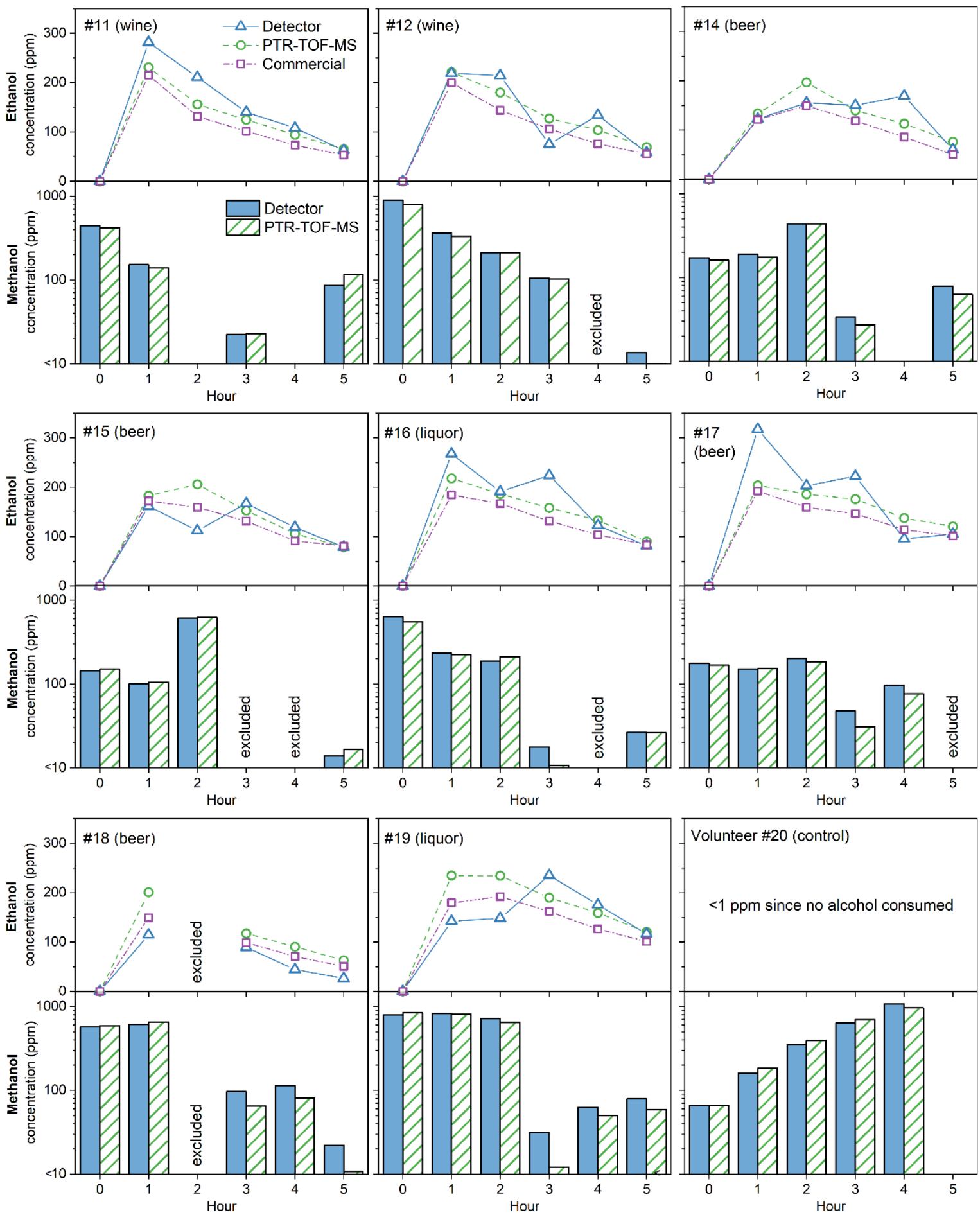

Figure S5. Breath ethanol concentrations (line plots) from volunteers \#11-20 as measured by our detector (triangles), a commercial breathalyzer (Dräger, squares) and the PTR-TOF-MS (circles). Methanol concentrations from the corresponding spiked samples (bar plots) as measured by the detector (solid bars) and PTR-TOF-MS (hatched bars). Profiles for volunteers \#10 and \#13 are given in the main manuscript. Excluded data points are due to insufficient breath sample provided by the volunteer or problems surfaced during sensor measurements. 


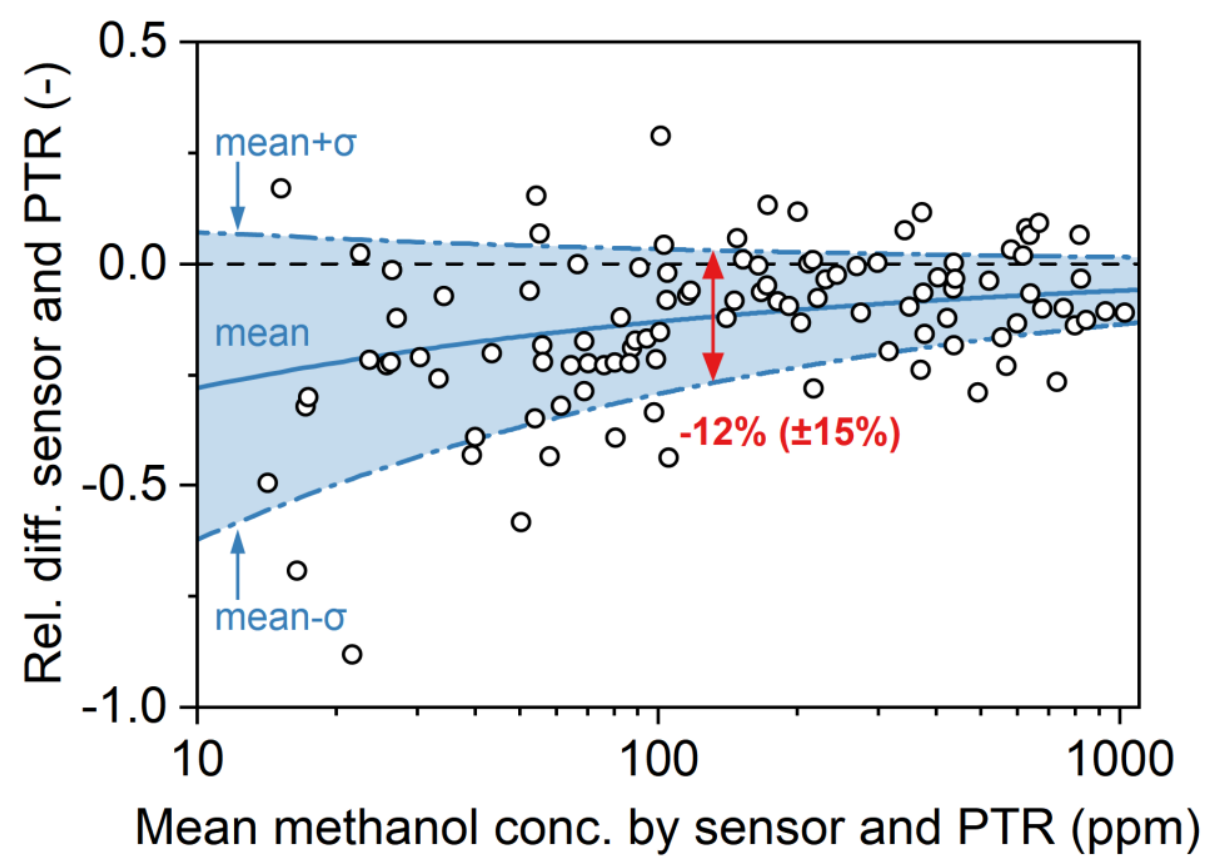

Figure S6. Bland-Altman plot of the relative difference in measured methanol concentration by sensor and PTR-TOF-MS as a function of the mean of both measurements. Mean (i.e., bias) and mean \pm standard deviation ( $\sigma$; i.e., precision) are indicated as solid and dasheddotted lines, respectively. Bias and precision are exemplarily shown at $131 \mathrm{ppm}$ (red arrow). 


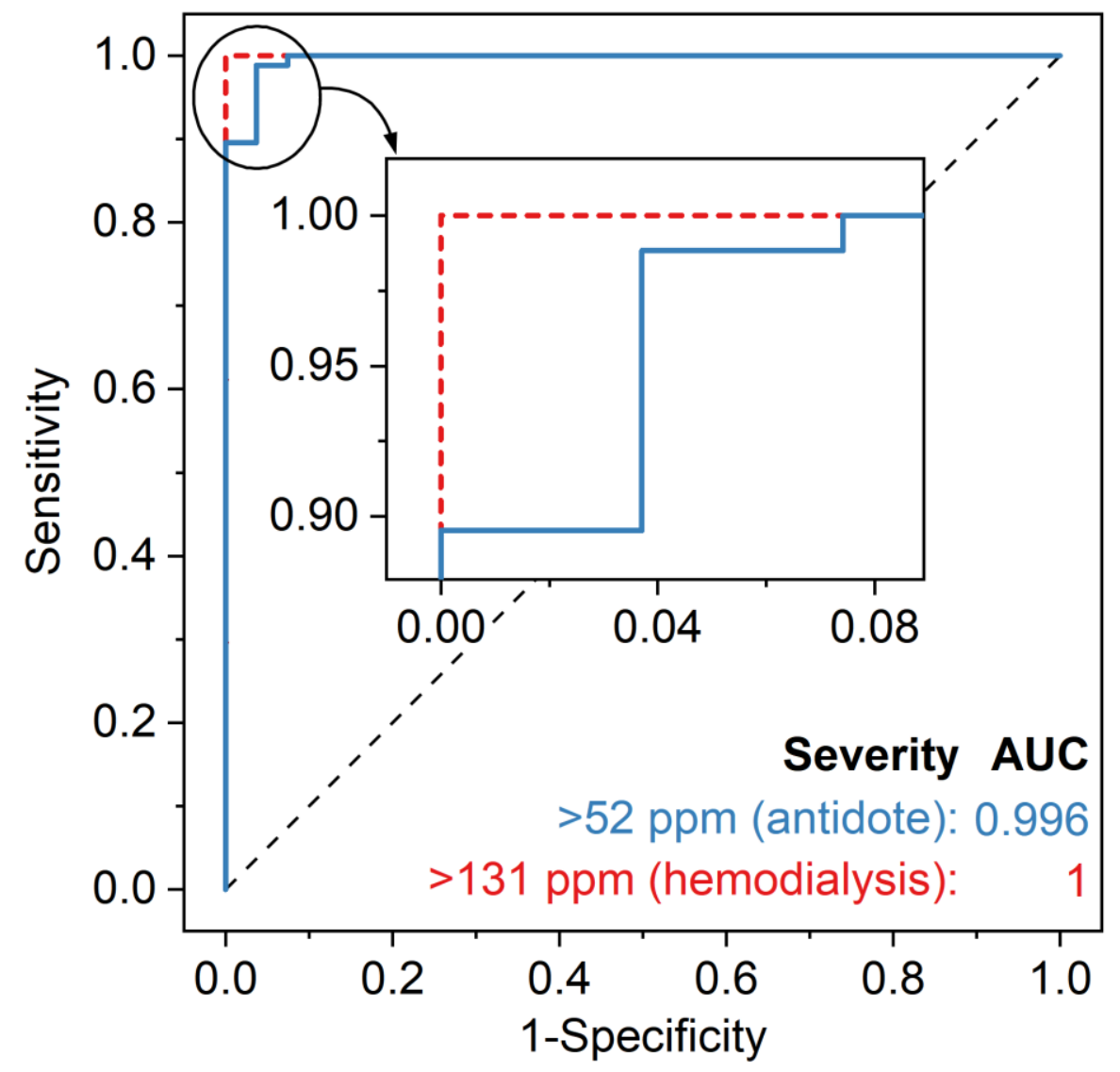

Figure S7. Receiver operating characteristic curves of the portable detector to classify breath methanol levels $>52 \mathrm{ppm}$ (blue) and >131 ppm (red) to guide treatment. Curves were determined based on Figure 5. These levels correspond to blood methanol levels (ratio $2901)^{20}$ where antidote and hemodialysis treatment are recommended. ${ }^{9}$ The respective area under the curves (AUCs) are indicated.

\section{References}

(9) Barceloux, D. G.; Randall Bond, G.; Krenzelok, E. P.; Cooper, H.; Allister Vale, J. American Academy of Clinical Toxicology practice guidelines on the treatment of methanol poisoning. J. Toxicol., Clin. Toxicol. 2002, 40, 415-446, DOI: 10.1081/CLT-120006745.

(19) Rostrup, M.; Edwards, J. K.; Abukalish, M.; Ezzabi, M.; Some, D.; Ritter, H.; Menge, T.; Abdelrahman, A.; Rootwelt, R.; Janssens, B. The methanol poisoning outbreaks in Libya 2013 and Kenya 2014. Plos One 2016, 11, e0152676, DOI: 10.1371/journal.pone.0152676.

(20) Laakso, O.; Haapala, M.; Jaakkola, P.; Laaksonen, R.; Luomanmäki, K.; Nieminen, J.; Pettersson, M.; Päivä, H.; Räsänen, M.; Himberg, J.-J. FT-IR breath test in the diagnosis and control of treatment of methanol intoxications. J. Anal. Toxicol. 2001, 25, 26-30, DOI: 10.1093/jat/25.1.26.

(22) Phillips, M. Breath tests in medicine. Sci. Am. 1992, 267, 74-79, DOI: 10.1038/scientificamerican0792-74. 